\title{
KONDISI LINGKUNGAN DAN KARAKTERISTIK SOSIAL BUDAYA UNTUK PENGELOLAAN DAERAH ALIRAN SUNGAI (Studi Kasus pada Suku Dani di Jayawijaya, Papua) \\ (Environmental conditions and socio-cultural characteristics for watershed management (Case study at Dani tribe, Jayawijaya, Papua)) \\ Baharinawati W. Hastanti \\ Balai Penelitian dan Pengembangan Teknologi Pengelolaan Daerah Aliran Sungai Jl. A. Yani Pabelan Kartasura PO BOX 295 Surakarta 57102 \\ Email: baharina_06@yahoo.co.id
}

Diterima: 23 Mei 2017; Selesai Direvisi: 16 Oktober 2017; Disetujui: 16 Oktober 2017

\begin{abstract}
Upper of Mamberamo watershed located at Jayawijaya regency, a plain (valley) in Jayawijaya mountains, that known as the Baliem valley. In this valley lies Tariratu river (Idenburg river) which is a tributary of Mamberamo river. Dani tribe, the oldest tribe inhabits this fertile region. In addition to known as belligerent, Dani tribe known as swidden farmers with certain traditional wisdom to maintain the soil fertility. Environmental condition and socio-cultural characteristics community in managing the upper watershed influence the watershed management, especially in the downstream. This study aims to determine the environmental and socio-cultural characteristics of the Dani tribe in managing the natural resources in the upper watershed to support Mamberamo watershed management. This study was conducted at Wamena, Jayawijaya regency, Papua province. This research is qualitative descriptive research. Data collections was conducted by interviews and literature studies. The data were analysed qualitatively and described the environmental conditions and socio-cultural characteristics of people in the upper watershed of Mamberamo or Baliem watershed is the major element in the management of the Mamberamo watershed. The upper watershed has a conservation function to reduce land degradation. The Dani tribe in the upper Mamberamo has local wisdoms that support the vegetation, soil and water conservation's function.
\end{abstract}

Key words: environmental; characteristics; socio; cultural; watershed

\begin{abstract}
ABSTRAK
Hulu Daerah Aliran Sungai (DAS) Mamberamo berada di Kabupaten Jayawijaya, suatu dataran (lembah) pada Pegunungan Jayawijaya, yang dikenal dengan Lembah Baliem. Pada lembah ini terbentang Sungai Tariratu (Sungai Idenburg) anak sungai Mamberamo. Suku Dani, suku tertua yang mendiami kawasan yang subur ini. Selain dikenal suka berperang, Suku Dani merupakan petani peladangan berpindah dengan kearifan tradisional tertentu untuk mempertahankan kesuburan tanahnya. Kondisi lingkungan maupun karakteristik budaya masyarakat dalam mengelola lahan di hulu DAS berdampak pada pengelolaan DAS di hilir. Penelitian ini bertujuan untuk mengetahui lingkungan dan karakteristik sosial budaya Suku Dani dalam pengelolaan sumber daya alam di hulu daerah aliran sungai untuk
\end{abstract}


mendukung pengelolaan DAS Mamberamo. Penelitian deskriptif kualitatif ini dilaksanakan di Wamena Kabupaten Jayawijaya, Provinsi Papua. Data dianalisis secara kualitatif dan diuraikan secara deskriptif. Pengumpulan data dilakukan dengan wawancara dan studi pustaka. Kondisi lingkungan di wilayah ini sebagian besar sangat curam. Pusat kegiatan pertanian dilakukan pada daerah yang datar. Sungai-sungai yang ada merupakan sungai gletsier yang arusnya deras dan rawan akan pengikisan, sedimentasi dan banjir. Kondisi lingkungan dan karakteristik sosial budaya masyarakat di hulu DAS Mamberamo atau Sub DAS Baliem merupakan unsur utama dalam pengelolaan DAS Mamberamo. Bagian hulu DAS merupakan kawasan dengan fungsi konservasi untuk pencegahan degradasi lahan. Masyarakat Suku Dani di hulu DAS Mamberamo mempunyai kearifan lokal yang mendukung fungsi konservasi vegetasi, tanah dan air.

Kata kunci: lingkungan; karakteristik; sosial;budaya; daerah aliran sungai

\section{PENDAHULUAN}

Daerah Aliran Sungai (DAS) dipandang sebagai ekosistem tata air dan digunakan sebagai unit pengelolaan sumberdaya alam vegetasi, tanah dan air yang rasional. DAS merupakan wilayah daratan dengan batas alam berupa punggung-punggung bukit sehingga tidak selalu berhimpitan dengan batas administrasi pemerintahan. Penggunaan DAS sebagai satuan wilayah pengelolaan adalah untuk memberikan pemahaman secara rasional dan obyektif. Setiap kegiatan yang dilakukan di suatu tempat (on site) di bagian hulu DAS memiliki dampak atau implikasi di tempat lain (off site) di bagian hilir DAS, atau sebaliknya bahwa pemanfaatan sumberdaya alam di wilayah hilir merupakan hasil dari daerah hulu yang secara daerah otonomi atau administrasi berbeda wilayah pengelolaannya (Paimin et al., 2012).

Sungai Mamberamo mempunyai dua anak sungai utama, yaitu Sungai Rouffaer/ Tariku yang mengalir dari arah barat ke timur dan Sungai Idenberg/ Taritatu yang mengalir dari arah timur ke barat. Panjang sungai sekitar $670 \mathrm{~km}$ dan debit rata-rata tahunan $5000 \mathrm{~m}^{3} /$ detik. Dua kawasan lindung yang berada di wilayah Mamberamo adalah: 1) Suaka Margasatwa Sungai Rouffer, dengan luas wilayah sekitar 310 ribu ha pada ketinggian $200 \mathrm{~m}$ dpl dan 2) Suaka Margasatwa Pegunungan Mamberamo Foya yang memiliki luas kawasan 1,10 juta ha. Bagian hilir DAS terdapat hutan rawa (hutan sagu), yang merupakan wilayah hutan primer alami. DAS Mamberamo dengan luas 7,8 juta ha merupakan salah satu areal lahan basah di Papua yang memiliki hutan rawa gambut 432,75 ha dan hutan rawa air tawar 14,43 ha (Tim Sintesis et al., 2008).

Kabupaten Jayawijaya dengan ibukota Wamena merupakan suatu wilayah di hulu DAS Mamberamo yaitu di wilayah Sub DAS Baliem. Kawasan ini berupa lembah pada Pegunungan Nassau (sekarang Pegunungan Jayawijaya). Orang biasa menyebut kawasan ini sebagai Lembah Baliem.

Suku Dani adalah suku tertua yang mendiami wilayah Lembah Baliem. Sebagai suku dengan tipikal yang suka berperang, 
Suku Dani mempunyai nilai-nilai budaya tertentu dalam mengelola sumber daya alam di wilayah lembah Baliem yang cocok sebagai wilayah pertanian.

Sebagai suatu ekosistem DAS bagian hulu adalah daerah konservasi, sedangkan DAS bagian hilir adalah daerah pemanfaatan. Kegiatan di daerah hulu akan berpengaruh pada daerah hilir dalam bentuk perubahan fluktuatif debit, transportasi sedimen serta materi yang terlarut (Asdak, 2010).

Dalam pengelolaan DAS Mamberamo, Lembah Baliem adalah daerah di bagian hulu DAS yang berfungsi perlindungan terhadap kelestarian DAS Mamberamo. Oleh karena itu, agar DAS tidak terdegradasi, wilayah tersebut harus dikelola dengan baik dengan memelihara kondisi tutupan vegetasi, mempertahankan kualitas air serta kemampuan menyimpan air.

Oleh sebab itu, perlu adanya tinjauan tentang kondisi lingkungan dan karakteristik sosial dan budaya masyarakat di bagian hulu DAS Mamberamo yaitu di Lembah Baliem. Tujuan penelitian ini adalah untuk mengetahui lingkungan dan karakteristik sosial budaya Suku Dani dalam pengelolaan sumber daya alam di hulu daerah aliran sungai untuk mendukung pengelolaan DAS Mamberamo.

\section{BAHAN DAN METODE}

\section{A. Waktu dan Lokasi}

Penelitian ini dilakukan pada bulan November 2016 di Wamena ibukota Kabupaten Jayawijaya, Provinsi Papua. Secara geografis terletak pada $138^{\circ} 30^{\prime}$ $139^{\circ} 40^{\prime}$ BT dan $3^{0} 45^{\prime}-4^{0} 20^{\prime}$ LS. Sebelah utara wilayah ini, berbatasan dengan Kabupaten Mamberamo Tengah dan Kabupaten Yalimo, sebelah timur berbatasan dengan Kabupaten Pegunungan Bintang, sebelah selatan berbatasan dengan Kabupaten Yahukimo dan bagian barat berbatasan dengan Kabupaten Lanny Jaya (Yasin, 2015).

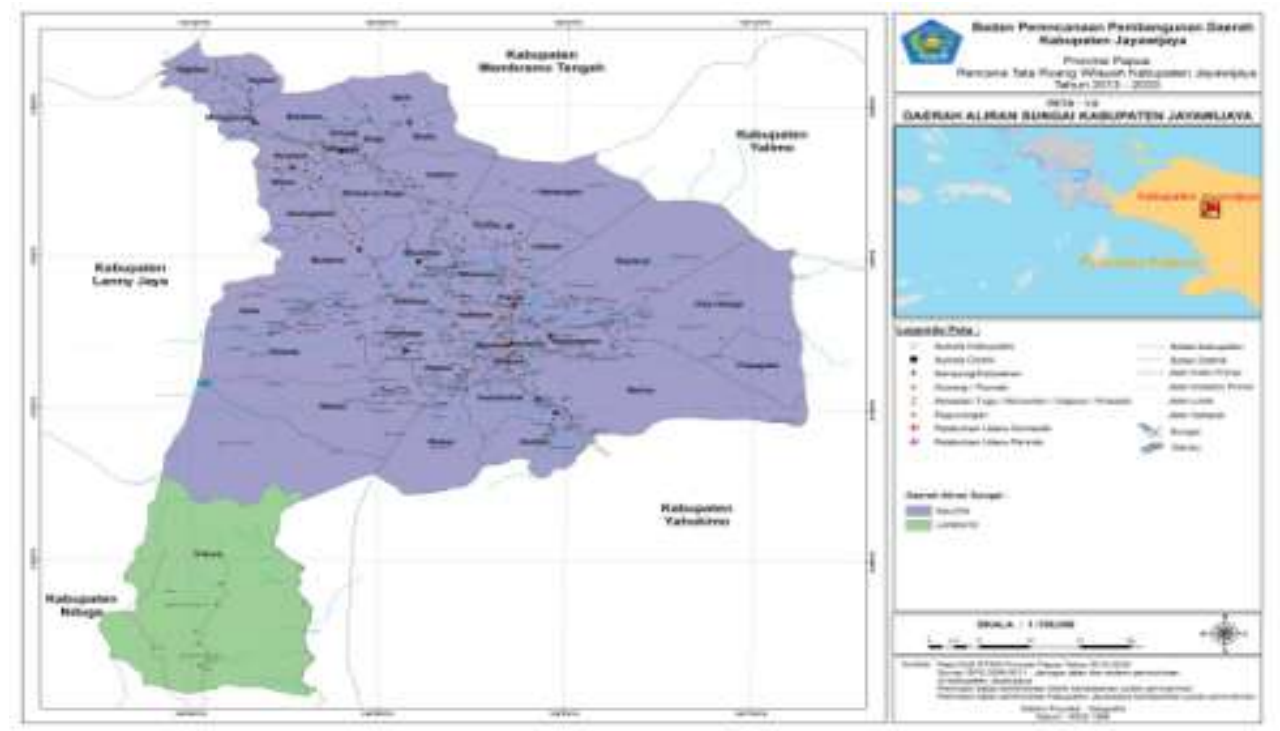

Gambar (figure) 1. Peta Kabupaten Jayawijaya (Hulu DAS Mamberamo) (Map of Jayawijaya Regency (Upper Mamberamo Watershed))

Sumber (source): Pemerintah Kabupaten Jayawijaya (Government of Jayawijaya Regency), 2015 


\section{B. Bahan dan Alat}

Alat dan bahan yang digunakan dalam penelitian ini adalah alat tulis, tally sheet, kamera dan recorder. Pengumpulan data dalam penelitian ini salah satunya adalah studi pustaka, maka bahan-bahan yang digunakan adalah: laporan-laporan, bukubuku referensi terkait dengan topik penelitian.

\section{Metode Penelitian}

1) Teknik pengumpulan data

Teknik pengumpulan data dalam penelitian ini adalah observasi atau pengamatan, interview atau wawancara dan dokumentasi (studi pustaka) (Moleong, 2009). Pengamatan dilakukan pada obyek penelitian berupa lingkungan biofisik di hulu DAS Mamberamo. Wawancara mendalam (depth interview) dilakukan kepada informan. Pemilihan informan dilakukan secara purposive yaitu kepala instansi terkait, tokoh adat, tokoh masyarakat dan tokoh agama. Dokumentasi atau studi pustaka dilakukan dengan cara mengumpulkan bahan-bahan literature yang terkait dengan obyek penelitian baik berupa buku dan laporan serta artikel di jurnal dan majalah.

2) Teknik analisis data

Penelitian ini adalah penelitian deskriptif. Data yang diperoleh dianalisis secara kualitatif serta diuraikan secara deskriptif (Moleong, 2009).

\section{HASIL DAN PEMBAHASAN}

\section{A. Gambaran lingkungan biofisik Lembah Baliem di Kabupaten Jayawijaya}

Lembah Baliem di Kabupaten Jayawijaya adalah suatu dataran berlembah pada
Pegunungan Jayawijaya, secara administratif wilayah ini termasuk dalam Kabupaten Jayawijaya. Wilayah lembah ini dibatasi Pegunungan Jayawijaya yang terkenal akan puncak-puncak salju abadinya, antara lain: Puncak Trikora (4.750 m dpl), Puncak Mandala (4.700 m dpl) dan Puncak Yamin (4.595 m dpl). Puncak Pegunungan Jayawijaya selalu ditutupi salju walaupun berada di kawasan tropis. Lereng pegunungan yang terjal dan lembah sungai yang sempit dan curam menjadi ciri khas pegunungan ini.

Cekungan lembah sungai yang cukup luas terdapat hanya di Lembah Baliem Barat dan Lembah Baliem Timur (Wamena). Vegetasi alam hutan tropis basah di dataran rendah memberi peluang pada hutan iklim sedang untuk berkembang cepat di lembah ini. Di lembah ini terbentang Sungai Baliem (Sungai Tariratu atau Idenburg) yang merupakan anak Sungai Mamberamo.

Lembah Baliem terletak pada ketinggian 1.600-2.000 m dpl. Temperatur udara bervariasi antara $14-25{ }^{\circ} \mathrm{C}$. Dalam setahun rata-rata curah hujan adalah $1.900 \mathrm{~mm}$ dan dalam sebulan kurang lebih 16 hari hujan. Musim hujan dan kemarau sulit dibedakan di wilayah ini. Berdasarkan data BMKG, bulan Maret merupakan bulan dengan curah hujan yang tertinggi, sedangkan curah hujan terendah terjadi pada bulan Juli (Kogoya, 2015).

Bentang alam Kabupaten Jayawijaya merupakan areal datar perbukitan dan pegunungan dengan kelerengan beragam, mulai $0 \%$ sampai lebih dari $40 \%$. Wilayah Kabupaten Jayawijaya selain berupa daerah kemiringan dengan klasifikasi 
sangat curam lebih dari $40 \%$. Daerah ini juga merupakan daerah yang rawan terhadap bencana. Daerah yang datar dan landai di Lembah Baliem berpotensi sebagai lahan pertanian dan pemukiman. Wilayah yang relatif datar yaitu sebesar (08\%) dan merupakan pusat kegiatan pertanian penduduk adalah wilayah Sub DAS Baliem sebagai bagian dari DAS Mamberamo (Tim sintesis et al., 2008).

Sungai-sungai di wilayah ini termasuk jenis sungai gletser dengan pola sungai yang deras airnya. Pola sungai seperti ini dapat mengakibatkan pengikisan tanah sepanjang alur sungai, proses sedimentasi dan banjir sepanjang cakupan sungai. Pola aliran air permukaan trellis dan sub dendritik dengan aliran yang intermiten dan permanen mengalir sepanjang tahun dan pada umumnya bermuara ke wilayah selatan Papua (Tim sintesis et al., 2008).

Jenis bencana alam yang sering terjadi antara lain bencana banjir, longsor, gempa bumi dan rawan gerakan tanah. Jenis tanah di wilayah ini terdiri dari sebagian besar jenis tanah alluvial, litosol, podsolik, dan batu karang metamorfik (filit, kuartit, chrit) sebagian dari lempengan pasifik yang terdesak tanggul-tanggul baltik. Keadaan penyebaran dari jenis tanah (Yasin, 2015), adalah sebagai berikut:

1) Daerah lembah terdapat jenis tanah alluvial

2) Daerah perbukitan terdapat jenis tanah litosol

3) Daerah dataran tinggi umumnya terdapat jenis podsolik coklat

Potensi air cukup bagus, hal tersebut ditunjukkan dengan pemanfaatan mata air di berbagai tempat yaitu di Distrik Napua,
Distrik Walesi, Distrik Kurulu, Distrik Libarek, Distrik Wollo, Distrik Siepkosi, Distrik Asologaima, Distrik Pyramid dan Distrik Yalengga. Pemanfaatan sumur gali di Distrik Wamena, Distrik Wouma dan Distrik Hubikiak. Keberadaan Danau Habema dengan luasan mencapai 2.461 ha yang terdapat di Distrik Walaik juga merupakan sumber air yang potensial (Tim sintesis et al., 2008).

Kemampuan lahan dalam menyimpan air tergantung pada kondisi permukaan lahan, seperti kondisi vegetasi, tanah dan lain-lain. Kondisi suatu DAS dikatakan baik jika memenuhi beberapa kriteria diantaranya debit sungai yang konstan sepanjang waktu, kualitas air yang baik, fluktuasi dan ketinggian air tanah tetap dari waktu ke waktu. Pengelolaan DAS berupaya untuk mengelola kondisi biofisik permukaan bumi sedemikian rupa sehingga menjamin distribusi air yang merata dengan hasil air yang maksimum dan mempunyai regim aliran yang optimum (Ichwana, 2014).

\section{B. Kondisi sosial ekonomi masyarakat Kabupaten Jayawijaya}

1) Perkembangan jumlah penduduk

Dinamika kependudukan di Kabupaten Jayawijaya selain disebabkan oleh faktor alamiah (kelahiran dan kematian) juga dipengaruhi oleh migrasi penduduk baik yang masuk maupun keluar wilayah ini. Trend pertumbuhan penduduk dilihat dari jumlah penduduk selama 4 tahun terakhir. Pertumbuhan penduduk dipengaruhi oleh tingginya angka kematian bayi di Kabupaten Jayawijaya yaitu 122 per 1000 kelahiran hidup dan tingginya angka 
migrasi keluar dari wilayah ini (BPS, 2014). kependudukan di Kabupaten Jayawijaya.

Tabel 1 menyajikan demografi

Tabel (Table) 1. Demografi kependudukan Kabupaten Jayawijaya (Demographic population of Jayawijaya regency)

\begin{tabular}{lrrrrr}
\hline \multicolumn{1}{c}{ Uraian (Description) } & \multicolumn{5}{c}{ Tahun (Year) } \\
& \multicolumn{1}{c}{2010} & 2011 & \multicolumn{1}{c}{2012} & \multicolumn{1}{c}{2013} & 2014 \\
\hline Jumlah Penduduk (Total Population) & 118.800 & 196.085 & 206.015 & 223.443 & 203.085 \\
\hline Jumlah KK (Number of household) & 29.100 & 49.021 & 51.504 & 55.861 & 50.771 \\
\hline $\begin{array}{l}\text { Kepadatan Penduduk (org/km) } \\
\text { Population density (person/kilometers) }\end{array}$ & 13,94 & 21,86 & 15,24 & 10,13 & 18,29 \\
\hline
\end{tabular}

Sumber (Source): BPS Kabupaten Jayawijaya (Central Bureau of Statistic Jayawijaya Regency), 2015

Kepadatan penduduk berpengaruh terhadap kinerja dan kerentanan DAS karena jumlah dan aktivitas penduduk berpengaruh terhadap kelestarian lahan. Semakin tinggi jumlah penduduk semakin besar pula tekanan pada lahan (Paimin et al., 2012). Demikian halnya dengan peningkatan jumlah penduduk di hulu DAS berdampak pada peningkatan kebutuhan lahan, sehingga berpengaruh pada pengelolaan DAS secara keseluruhan (Taena, 2016). Kepadatan penduduk di wilayah hulu DAS Mamberamo tergolong rendah dibandingkan dengan tingkat pertumbuhan penduduk di hulu DAS kritis Cidanau yang mencapai ribuan jumlahnya (Salminah et al, 2014). Wilayah dengan kepadatan tinggi akan berisiko terhadap kerusakan lingkungan karena tingginya intensitas pemanfaatan air dan lahan (Dirjen Pengelolaan DAS, 2013). Oleh sebab itu wilayah hulu DAS Mamberamo kurang berisiko terhadap kerusakan lingkungan karena kepadatan penduduknya rendah, sehingga intensitas pemanfaatan air rendah.

2) Rasio ketergantungan penduduk

Rasio ketergantungan penduduk di Kabupaten Jayawijaya adalah 35,90 (Pemerintah Provinsi Papua, 2016). Hal ini dapat diartikan bahwa setiap 100 orang penduduk usia produktif menanggung beban 36 orang penduduk tidak produktif. Rasio ketergantungan penduduk merupakan salah satu indikator tingkat kemiskinan di suatu wilayah. Angka rasio ketergantungan penduduk di Kabupaten Jayawijaya merupakan rambu-rambu kewaspadaan terhadap angka kemiskinan di hulu DAS Mamberamo. Rasio ketergantungan pendududuk di Kabupaten Jayawijaya tergolong rendah, sehingga tidak rentan terhadap kemiskinan, oleh sebab itu tidak mengancam pengelolaan DAS. Kemiskinan masyarakat di hulu DAS merupakan salah satu permasalahan dalam pengelolaan DAS, karena berakibat pada tekanan terhadap lahan, terutama terjadinya alih fungsi kawasan lindung (Giyarsih et al., 2011).

\section{3) Tingkat pendidikan}

Tingkat pendidikan penduduk di Kabupaten Jayawijaya dipengaruhi oleh kemiskinan dan isolasi geografis yang berakibat pada minimnya sarana pendidikan maupun sedikitnya jumlah pengajar. Persentase tingkat pendidikan penduduk di Kabupaten Jayawijaya disajikan dalam Tabel 2. 
Tabel (Table) 2. Persentase tingkat pendidikan penduduk Kabupaten Jayawijaya (Percentage of education level of population at Jayawijaya Regency)

\begin{tabular}{lrrr}
\hline & \multicolumn{2}{c}{ Jenis Kelamin (Sex) } & Jumlah \\
\cline { 2 - 3 } Uraian (Description) & $\begin{array}{c}\text { Laki-laki } \\
\text { (Male) }\end{array}$ & $\begin{array}{c}\text { Perempuan } \\
\text { (Female) }\end{array}$ & $\begin{array}{c}\text { (Total) } \\
\text { Tidak Bersekolah (No school) }\end{array}$ \\
Sekolah Dasar (Primary school) & 37,68 & 57,60 & 47,52 \\
Sekolah Lanjutan Pertama (Junior high school) & 11,02 & 13,22 & 12,14 \\
Sekolah Lanjutan Atas (Senior high school) & 19,16 & 14,03 & 16,03 \\
Diploma 1 / Diploma 2 (College) & 23,38 & 10,97 & 17,25 \\
Sarjana Muda (Baccalaurate) & 0,73 & 0,29 & 0,51 \\
Sarjana/ Pascasarjana (Bachelor/ postgraduate) & 1,70 & 1,41 & 1,56 \\
\hline Total (Total) & 6,27 & 2,46 & 4,39 \\
\hline
\end{tabular}

Sumber (Source): BPS Kabupaten Jayawijaya (Central Bureau of Statistic Jayawijaya Regency), 2015

Tingkat pendidikan akan mempengaruhi perilaku dan pengetahuan masyarakat pada pengelolaan DAS. Tingkat pendidikan masyarakat di Kabupaten Jayawijaya yang rendah akan mempengaruhi kurangnya pemahaman masyarakat terhadap pengelolaan DAS. Kurangnya pemahaman masyarakat dalam mengelola lingkungan akan menyebabkan rusaknya DAS (Giyarsih et al., 2011).

\section{Nilai-nilai kehidupan Suku Dani}

Keberadaan masyarakat lokal di hulu DAS Mamberamo adalah modal sosial (social capital) dalam pengelolaan DAS. Salah satu pendekatan dalam pengelolaan DAS adalah pendekatan partisipatoris, yaitu melibatkan masyarakat lokal dalam pengambilan keputusan atau sebagai subyek dalam pengelolaan DAS. Pendekatan partisipatoris dapat dilaksanakan dengan memahami nilai-nilai budaya masyarakat setempat (penduduk asli).

Penduduk asli yang mendiami Lembah Baliem di Jayawijaya terdiri dari 4 suku besar, yaitu Suku Dani, Suku Yali, Suku Lanny dan Suku Nduga. Suku Dani merupakan suku terbesar dan tertua yang mendiami lembah Baliem. Masyarakat Suku Dani biasa menyebut dirinya sebagai Orang Parim (Veronica, 2013). Walaupun dikenal sebagai suku yang suka berperang, namun umumnya orang Dani menolak dikatakan sebagai pengayau.

Sebagian besar Suku Dani memeluk agama Kristen Protestan, namun tidak bisa lepas dari adat istiadatnya sebagai penganut kepercayaan pada roh-roh orang yang sudah meninggal. Bentuk kepercayaannya itu terlihat pada Orang Dani yang masih melakukan ritual-ritual adat untuk menghormati arwah leluhur dan kerabatnya. Dalam kehidupan seharihari Orang Dani masih menggunakan peralatan tradisional berupa: tombak, kapak, parang, busur dan anak panah. Senjata-senjata tersebut digunakan untuk perang suku, berburu dan kesenian, maupun pelengkap pakaian adat.

Makanan pokok Orang Dani adalah ubi jalar yang dalam Bahasa Dani disebut ifere, petatas atau hipere. Dalam acara-acara penting dan ritual adat, Orang Dani akan melakukan bakar batu, yaitu tradisi memasak hipere (ubi jalar), sayuran dan daging hasil buruan (babi), dengan cara 
menimbun makanan di dalam lubang dengan batu-batu yang dibakar dalam api yang membara.

Orang Dani terkenal dengan pakaian adat koteka (kebe/ kobogwa) dan salli. Koteka adalah labu kering yang digunakan untuk menutupi alat kelamin laki-laki. Salli adalah rok yang terbuat dari rumbairumbai jerami yang dipakai oleh perempuan Suku Dani (Mabe et al., 2016). Dalam peperangan dan ritual adat, koteka akan dipadukan dengan penutup kepala dan asesoris berupa gelang, kalung dan gelang kaki beserta senjata tradisional busur, anak panah, tombak, parang dan sebagainya (Nahuway, 2014).

Mata pencaharian Orang Dani umumnya adalah berkebun, berburu, beternak serta mencari ikan di sungai. Pada umumnya hasil yang diperoleh akan dikonsumsi keluarga besarnya atau ditukar dengan barang yang diperlukan. Kelompok kekerabatan terkecil dari Suku Dani adalah keluarga luas yang terdiri dari beberapa keluarga inti. Keluarga luas ini tinggal di suatu kompleks yang terdiri dari rumahrumah kecil/ honai menyerupai sekat-sekat berpagar yang disebut silimo (Nahuway, 2014). Silimo biasa yang dihuni oleh masyarakat biasa dikepalai oleh $A p$ Waregma (Albaiti, 2015).

Struktur bermasyarakat Suku Dani merupakan gabungan dari beberapa klan kecil yang disebut ukul, dan klan besar yang disebut ukul oak. Kesatuan teritorial yang terkecil dalam masyarakat Dani adalah kompleks perumahan (uma) yang dihuni untuk kelompok keluarga luas yang patrilineal (diturunkan kepada anak lakilaki) (Djawaru \& Panjaitan, 2014).
Organisasi kemasyarakatan pada suku Dani ditentukan berdasarkan hubungan keluarga dan keturunan yang berdasarkan pada kesatuan teritorial. Suku Dani dipimpin oleh seorang kepala suku besar yaitu disebut $A p$ Kain yang memimpin desa adat watlangka, selain itu ada juga 3 kepala suku yang posisinya berada di bawah Ap Kain dan memegang bidang sendiri, mereka adalah: Ap Menteg, Ap Horeg, dan Ap Ubaik.

Sistem kepemimpinan tradisional masyarakat Dani ditunjukkan dengan adanya istilah kain untuk pria yang berarti kuat, pandai dan terhormat. Pada tingkat uma, pemimpinnya adalah laki-laki yang sudah tua tetapi masih mampu mengatur urusannya dalam satu halaman rumah tangga maupun kampungnya. Urusan tersebut antara lain: pemeliharaan kebun dan babi, serta melerai pertengkaran.

Pemimpin perang pada Suku Dani disebut win metek. Syarat-syarat yang harus dipenuhi oleh win metek adalah memiliki kekuatan fisik dan keberanian, bersifat murah dan baik hati, pandai berburu, pandai berperang dan juga pandai bercocok tanam. Win metek bukan hanya pemimpin perang namun juga pemimpin konfederasi. Wewenangnya selain memimpin perang juga memimpin masyarakat dalam kegiatan sehari-hari (Nahuway, 2014).

Bahasa daerah Suku Dani yang mendiami wilayah Lembah Baliem adalah bahasa-bahasa yang masuk dalam Bahasa Papua dari Phylum Trans-New Guinea (Nahuway, 2014). Bahasa daerah yang digunakan pun mempunyai perbedaan dialog dan pengucapan antar satu wilayah 
dengan wilayah lainnya walaupun masih berada dalam jangkauan jarak tempuh yang boleh dikatakan masih dekat. Secara garis besar Bahasa Dani terbagi dalam tiga bagian bahasa yaitu, Bahasa Dani Lembah (daerah sekitar Kota Wamena/ Kabupaten Jayawijaya), Bahasa Dani Barat (daerah bagian barat Kota Wamena (Kabupaten Lany Jaya, Kabupaten Puncak Jaya, dan Kabupaten Tolikara) serta Bahasa Dani Timur/ Bahasa Yali (Kabupaten Yahokimo dan Kabupaten Yalimo) (Nahuway, 2014). Namun masyarakat lokal di Lembah Baliem sendiri sebagian besar sudah dapat menggunakan bahasa Indonesia dengan dialek atau logat Wamena/ Papua.

Kesenian masyarakat Suku Dani dapat dilihat dari cara membangun tempat kediaman, seperti pilamo, ebeai dan wamai. Selain membangun tempat tinggal, masyarakat Dani juga mempunyai seni kerajinan khas seperti anyaman kantong jaring penutup kepala (noken) dan pengikat kapak. Orang Dani pun mempunyai berbagai peralatan yang terbuat dari bata. Peralatan tesebut antara lain: moliage (sejenis kapak batu dengan ujung terbuat dari besi), valuk sage (alat sejenis tugal untuk melubangi tanah), wim (busur panah), kurok (sejenis parang), dan panah sege (Indriyawati, 2009).

Sebagai wujud penghormatan mereka terhadap nenek moyang atau leluhurnya, secara turun temurun, pola seni ukir yang dibuat oleh Suku Dani selalu dikaitkan pada kepercayaan mereka terhadap leluhur. Ada 3 macam warna yaitu merah, hitam, dan putih yang selalu digunakan oleh Suku Dani pada beberapa hasil ukirannya. Merah melambangkan daging, putih menggambarkan tulang, sementara hitam melambangkan warna kulit dari Orang Dani itu sendiri. Pembuatan seni ukir pada Suku Dani menggunakan alat pahat tradisional yang terbuat dari kayu jambu batu dan batu kali.

\section{Pola pemanfaatan lahan pada Suku Dani}

1) Rumah (sili)

Rumah (sili) merupakan kesatuan teritorial terkecil dari Suku Dani yang ditempati oleh beberapa keluarga yang mempunyai ikatan pertalian darah. Sili terdiri dari bangunan-bangunan berupa pilamo (honai khusus laki-laki), ebei (honai khusus perempuan dan anak), hunina (honai untuk menyimpan makanan dan dapur), wamai/ wamdabu (honai untuk kandang babi), wadloleget (tempat keramat), silimo (halaman untuk menggelar ritual adat dan tempat bermain anak-anak), wen ukutlu (pekarangan kecil di sekitar honai). Sili akan dikelilingi pagar kayu yang rapat (leget) dengan satu pintu untuk keluar masuk (mukarai) (Djawaru, 2014).

Honai dibangun begitu mungil dengan tinggi sekitar 2,5 meter dan terbagi 2 lantai, sehingga apabila masuk ke dalamnya kita tidak bisa berdiri. Dalam honai terdapat perapian yang digunakan untuk menghangatkan badan jika udara terasa dingin. Apabila perapian menyala, honai akan terasa sesak oleh asap karena kurangnya ventilasi.

Bahan bangunan pembuat honai terdiri dari jenis-jenis tanaman tertentu yang tumbuh di kawasan hutan sekitar permukiman. Kayu yang digunakan untuk 
dinding luar bangunan (honai, ebei dan wamai) adalah kulit kayu Araucaria cuninghamii dengan panel terbuat dari dari kayu sengon (Albizia moluccana) dan jenis kayu keras lainnya. Panel dinding bagian dalam terbuat dari kayu jenis melur (Podocarpus papuana). Atap bangunan biasanya terbuat dari jenis alang-alang (Imperata cylindrica) dan jenis rotan (Calamus spp) (Albaiti, 2015).

Jenis-jenis tanaman ini sangat berarti dalam konservasi tanah, sehingga jika terlalu sering diambil akan terjadi kerusakan yang berakibat fatal pada erosi dan sedimentasi. Oleh karena itu perlu pengaturan lokal dalam pengambilan jenis kayu ini atau diatur secara adat agar tidak mudah ditebang untuk diambil kayunya. Misalnya dengan aturan-aturan seperti: pengambilan tanaman-tanaman tersebut harus seijin kepala suku, pengambilan tanaman harus disertai penanaman jenis tersebut dan adanya sanksi adat yang dibebankan kepada masyarakat yang melanggar aturan-aturan adat tersebut.

2) Perkampungan (ouna)

Perkampungan atau ouna dalam Bahasa Dani, adalah satuan permukiman yang terdiri dari beberapa sili. Suatu perkampungan tradisional masyarakat Suku Dani biasanya ditandai dengan adanya tanaman-tanaman tertentu yang mempunyai manfaat untuk kehidupan sehari-hari yaitu pohon cemara (Cassuarina spp) dimanfaatkan sebagai tanaman pelindung, buah merah (Pandanus conodeus) adalah tanaman pangan lokal di Papua, pohon pisang (Musa spp), hanjuang/ andong (Cordyline spp) digunakan untuk ritual adat.

\section{3) Kebun tanaman pangan (wen hipere)}

Lahan untuk menanam tanaman pangan ini biasanya ditanami tanaman utama berupa ubi jalar (Ipomea batatas) yang dalam Bahasa Dani disebut ifere atau hipere. Selain ditanami ubi jalar, lahan ini juga ditanami berbagai jenis tanaman pangan seperti sayur lilin (Setaria palmifolia), kecipir (Psococarpus tetragonolobus), uwi (Dioscorea spp), keladi (Celocasia esculenta), dan tembakau (Nicotina tabaccum). Pada perkembangannya wen hipere juga ditanami jagung (Zea mays), singkong (Manihot esculenta), kubis (Brassica oleracea) dan jenis sayuran lainnya (Purwanto, 2003).

4) Kebun tanaman introduksi (wen het)

Lahan kebun ini mengadopsi lahan milik pendatang. Tanaman-tanaman yang ditanam di kebun ini adalah jenis-jenis tanaman baru hasil introduksi dari luar yaitu kedelai (Glycine max), kacang tanah (Arachis gypogea), kacang kratok (Phaseolus lunatus), kubis (Brassica oleracea var brotytis), sawi (Brassica rapa), Bokcoy (Brassica chinensis), bloem kol (Brassica oleracea var. capitata), labu siam (Sechium edule), wortel (Daucus carota), bayam (Amaranthus spp), bawang merah (Allium cepa), bawang putih (Allium sativum), dan tomat (Lycopersicon esculentum) (Purwanto, 2003).

5) Sawah (wen nasi)

Lahan ini merupakan hasil introduksi penanaman tanaman pangan baru kepada masyarakat Suku Dani di Lembah Baliem. Penanaman padi sawah pertama dikenalkan oleh guru dari Toraja yang membawa bibit padi asal Sulawesi untuk 
ditanam di Baliem, sekitar tahun 1974 (Purwanto, 2003).

Pada tahun 1980 Dinas Pertanian Kabupaten Jayawijaya secara resmi memulai penanaman padi di kawasan ini untuk menambah diversitas pangan lokal dan meningkatkan ekonomi masyarakat di Lembah Baliem. Pada tahun 1990-an tanaman padi di Kabupaten Jayawijaya termasuk di kawasan Lembah Baliem semakin berkembang dengan pesat, didukung dengan pembangunan infrastruktur pengairan sawah. Pengembangan padi di sawah ditingkatkan untuk mengurangi pasokan padi dari luar dan meningkatkan pendapatan masyarakat setempat.

6) Lahan bekas kebun (wen kulama)

Lahan ini adalah bekas kebun Suku Dani yang sengaja dibiarkan sebagai lahan masa bera. Pada dasarnya masyarakat Suku Dani sama dengan masyarakat lokal lainnya di Papua, mengusahakan pertanian dengan cara perladangan berpindah. Perlakuan ini bertujuan untuk memulihkan kesuburan tanah pada lahan yang telah ditanami. Wen kulama merupakan hutan sekunder bekas ditanami hipere yang akan dibiarkan selama 5 sampai 15 tahun.

Pada umumnya masyarakat akan menanami kembali dengan melihat tanda bahwa pohon-pohon yang tumbuh atau ditanam sudah dapat menghasilkan biji untuk anakan. Masyarakat Suku Dani mengenal 2 jenis lahan masa bera (wen kulama), yaitu 1) wen kulama kitma, lahan dengan masa bera 0-5 tahun atau hutan sekunder tua, dan 2) wen kulama alekma, lahan bera lebih 5 tahun atau hutan sekunder tua.
Tanaman yang mendominasi wen kulama kitma atau hutan sekunder muda adalah jenis-jenis tanaman bawah seperti Imperata cylindrica, Leersia hexandra, Wendlania paniculata, Dodonaea viscosa, Pittosporum ramiflorum, Polygonium capathipolium, Grevillea papuana (Purwanto, 2003). Adapun wen kulama alekma atau hutan sekunder ditandai dengan vegetasi jenis-jenis herba seperti Melastoma malabarica, Wendlandia paniculata, Pittosporum ramiflorum, $P$. ferrugenium, Grevillea papuana, Schefflera macrostachya, Glochidion vinkianum, dan Dodonaea viscosa (Purwanto, 2003).

7) Hutan primer (okama)

Bagi masyarakat Suku Dani di Lembah Baliem, hutan adalah tempat tumbuhnya pohon-pohon besar (yang berkayu) dan segala jenis tumbuhan dan hewan. Hutan adalah tempat memenuhi kebutuhan hidup Masyarakat Dani sehari-hari. Hutan Primer di kawasan Lembah Baliem saat ini sulit ditemukan, yang ada adalah hutan bekas tebangan atau hutan sekunder dengan umur 20-30 tahun (Purwanto, 2003).

8) Tempat keramat (wakunmo dan wesama)

Lahan ini merupakan tempat keramat yang tidak bisa dimasuki seseorang secara sembarang. Hanya tokoh-tokoh adat ( $A p$ metek/ kepala suku) bisa memasuki hutan terlarang ini. Kawasan ini merupakan tempat untuk menyimpan mayat yang ditandai dengan adanya tombak (sege) yang dibungkus dengan daun alang-alang dan rotan yang diletakkan di lahan tersebut. Kawasan keramat ini dalam pengawasan sanak kerabat sang mayat. 
Tidak seorang pun warga biasa yang berani memasuki kawasan ini, apalagi mengambil dan menebang pohon-pohon yang ada. Kawasan ini bagaikan hutan primer dengan vegetasi-vegetasi besar dan rapat (Veronica, 2013).

\section{9) Lahan tergenang (yelesimo)}

Kawasan ini merupakan lahan yang selalu tergenang air (rawa-rawa), sehingga bagi Orang Dani tidak cocok untuk ditanami tanaman pangan terutama hipere (Purwanto, 2003). Oleh sebab itu biasanya digunakan untuk beternak babi. Babi merupakan harta yang bernilai tinggi bagi Orang Dani, karena selain bernilai adat juga bernilai ekonomi. Masyarakat Suku Dani tidak dapat dipisahkan dari kegiatan beternak babi. Selain bernilai jual tinggi sebagai harta, babi merupakan mas kawin dan alat rekonsiliasi dalam perang suku (Veronica, 2013).

\section{E. Peran Kondisi sosial budaya Suku Dani untuk pengelolaan DAS}

DAS Mamberamo merupakan suatu megasistem, dimana kompleksitas ekosistem DAS mensyaratkan suatu pendekatan pengelolaan yang bersifat multisektoral, lintas daerah, termasuk kelembagaan dengan kepentingan masingmasing serta mempertimbangkan prinsip saling ketergantungan (Suprayogi et al., 2015). Dalam hal ini juga perlu mempertimbangkan kelembagaan adat Suku Dani yang bermukim di hulu DAS Mamberamo beserta segala kepentingan masyarakat di dalamnya, dengan prinsip mengutamakan saling ketergantungan satu sama lain baik secara multisektoral, lintas daerah maupun kelembagaannya. Hal-hal dalam pengelolaan DAS yang perlu diperhatikan yaitu: 1) terdapat keterkaitan antara berbagai kegiatan dalam pengelolaan sumber daya alam dan pembinaan aktivitas manusia dalam pemanfaatan sumber daya alam, 2) melibatkan berbagai disiplin ilmu dan mencakup berbagai kegiatan yang tidak selalu saling mendukung, dan 3) meliputi daerah hulu, tengah dan hilir yang mempunyai keterkaitan biofisik dalam bentuk daur hidrologi untuk ekosistem (Suprayogi et al., 2015).

Pengelolaan DAS harus memenuhi aspek-aspek lingkungan, sosial dan ekonomi, karena pengelolaan DAS dimaksudkan untuk memberikan manfaat ekonomi yang sebesar-besarnya bagi manusia, terutama bagi masyarakat lokal dan masyarakat miskin dengan tidak mengabaikan kelestarian lingkungan serta mewujudkan masyarakat yang mandiri dan patisipasif (Emilia, 2013). Oleh karena itu, pengelolaan DAS Mamberamo harus memberikan manfaat ekonomi untuk masyarakat sekitar DAS, terutama masyarakat lokal Suku Dani dan suku-suku lainnya.

Kearifan lokal Suku Dani dalam penataan lahan, terutama dalam pembagian lahan untuk kebun, bekas kebun, hutan primer maupun tempat keramat, selain berfungsi untuk memelihara kesuburan tanah dan mempertahankan vegetasi juga turut mendukung pengelolaan DAS, karena penutupan lahan oleh vegetasi dengan segala bentuknya dapat mempengaruhi aliran air. Vegetasi dan tutupan lahan berupa hutan alam, regenerasi tanaman hutan, budidaya pohon sebagai tanaman 
pagar maupun hutan tanaman baik monokultur maupun agroforestri dapat mempengaruhi aliran air intersepsi, perlindungan agregat tanah, infiltrasi maupun air serapan (Suprayogi et al., 2015).

Perencanaan pengelolaan DAS yang efektif, tidak hanya didasarkan pada kondisi fisik DAS tersebut, tetapi juga harus berdasarkan informasi kondisi sosial masyarakat. Hal ini ditujukan agar sistem pengelolaan DAS tersebut sesuai dengan kondisi dan kebutuhan masyarakat lokal (Salminah et al., 2014). Pemahaman terhadap karakteristik sosial budaya masyarakat dan karakteristik biogeofisik DAS penting untuk mengetahui kondisi suatu DAS dalam rangka kebijakan makro pengelolaan DAS (Sari et al., 2014).

Peran kelembagaan sosial dan budaya dalam pengelolaan DAS sangat besar karena mengatur tingkah laku manusia dalam pemanfaatan dan pelestarian lingkungan DAS. Lembaga ini mencakup norma, simbol, kepercayaan, peraturan adat/ masyarakat dan status yang mempengaruhi kehidupan masyarakat, seperti keagamaan, pendidikan, ekonomi dan manajemen kehidupan (Darmanto et al., 2015). Pada Suku Dani di hulu DAS Mamberamo, lembaga sosial berupa lembaga adat sangat dipatuhi oleh masyarakatnya. Para pelanggar lembaga sosial diberikan sanksi sosial berupa hukuman adat dan pencitraan yang buruk dari masyarakat adatnya.

Peran pimpinan atau tokoh masyarakat penting dalam pemberdayaan, penataan dan kelangsungan kehidupan masyarakat. Dalam pengelolaan DAS yang melibatkan peran multipihak, seorang pemimpin tradisional dapat berfungsi sebagai katalis yang membantu kelancaran proses perubahan. Salah satu fungsi pemimpin adalah untuk menumbuhkan kepercayaan dalam membangun jejaring sosial, karena kepercayaan bisa menjadi pelumas bagi keberlangsungan suatu program kerjasama multipihak yang diperlukan dalam pengelolaan DAS (Suradisastra \& Pasandaran, 2012).

Karakteristik DAS mencakup iklim, biofisik DAS, hidrologi serta sosial ekonomi budaya yang berada di dalam wilayah DAS sekitar DAS. Karakteristik DAS adalah salah satu unsur utama dalam pengelolaan DAS seperti dalam perencanaan, monitoring dan evaluasi sebagaimana tertuang dalam Keputusan Menteri Kehutanan No 52/KptsII/2001 tentang penyelenggaraan DAS sebagai ekosistem, wilayah (geografi), geobiofisik, sumber daya alam, sumber daya manusia, kegiatan-kegiatan multisektor dan aspek sosial ekonomi budaya (Triono, 2010).

Demikian halnya dengan pengelolaan DAS Mamberamo sebagai suatu ekosistem. Karakteristik DAS Mamberamo perlu diperhatikan terutama kaitannya dengan kondisi geogafi, geobiofisik, sumber daya alam, sumber daya manusia maupun kegiatan-kegiatan multisektoral maupun aspek sosial budaya pada wilayah DAS Mamberamo baik bagian hulu, tengah maupun hilir.

Disamping itu dalam pengelolaan DAS terpadu, juga diperlukan batasan-batasan mengenai DAS berdasarkan fungsi, DAS bagian hulu didasarkan pada fungsi konservasi yang dikelola untuk 
mempertahankan kondisi lingkungan DAS agar tidak terdegradasi (Tresnadi, 2008). Wilayah Lembah Baliem (Wamena) sebagai DAS bagian hulu harus berfungsi untuk mempertahankan kondisi lingkungan agar terjaga dari degradasi lingkungan. Beberapa kearifan lokal masyarakat Suku Dani di Wamena baik dalam kelembagaan adat maupun pengelolaan sumber daya alamnya patut menjadi pertimbangan dalam pengelolaan DAS.

\section{KESIMPULAN}

Kondisi lingkungan dan karakteristik sosial budaya masyarakat di hulu DAS Mamberamo atau Sub DAS Baliem merupakan unsur utama dalam pengelolaan DAS Mamberamo dengan mempertimbangkan karakteristik lingkungan, sosial dan budaya Suku Dani yang berdiam di wilayah Lembah Baliam di hulu DAS Mamberamo. Bagian hulu DAS merupakan kawasan dengan fungsi konservasi untuk pencegahan degradasi lahan. Masyarakat Suku Dani di hulu DAS Mamberamo mempunyai kearifan lokal yang mendukung fungsi konservasi vegetasi, tanah dan air dalam pola pemanfaatan lahan dalam sistem perladangan berpindah yang dianut secara turun temurun. Disamping itu peran pemimpin dalam kelembagaan adat Suku Dani juga perlu diperhitungkan sebagai tokoh yang dipatuhi masyarakatnya dan dapat dijadikan katalisator dalam perubahan. Selanjutnya kondisi lingkungan dan karakteristik sosial budaya Suku Dani dapat dijadikan masukan untuk kebijakan pengelolaan DAS Mamberamo, khususnya Sub DAS Baliem di Papua.

\section{UCAPAN TERIMA KASIH}

Terimakasih kepada Pemerintah Daerah Kabupaten Jayawijaya dan masyarakat adat Suku Dani di Wamena Lembah Baliem, para narasumber dan semua pihak yang membantu.

\section{DAFTAR PUSTAKA}

Albaiti, A. (2015). Kajian kearifan lokal kelompok budaya Dani Lembah Baliem Wamena Papua. Jurnal Pendidikan Nasional Indonesia, 1(1), 14-33.

Asdak, C. (2010). Hidrologi dan pengelolaan daerah aliran sungai (Edisi Kelima). Yogyakarta: Gadjah Mada University Press.

Darmanto, D., Tyas, D., \& Shafarani, F. (2015). Aspek kelembagaan dalam pengelolaan daerah aliran sungai. Yogyakarta: Gadjah Mada University Press.

Emilia, F. (2013). Pengelolaan sumber daya alam berbasis masyarakat dalam upaya konservasi daerah aliran sungai (Studi kasus Desa Keseneng, Kecamatan Sumowono, Kabupaten Semarang). Tesis. Program Magister Ilmu Lingkungan Universitas Diponegoro Semarang .

Djawaru, F., \& T.Panjaitan. (2014). Mitologi dan gender dalam arsitektur Suku Dani. Universitas Indonesia. Retrieved from

http://lib.ui.ac.id/naskahringkas/2015 -11/S55621-Mukrima Fauriska Djawaru

Giyarsih, S., Abdi, Z., Ma'mun, S., Hasanati, S., Sitohang, L., \& Junaidi, I. (2011). Analisa karakter sosial ekonomi dan sinergi kelembagaan sebagai bentuk pengelolaan daerah aliran sungai terpadu dalam potensi dan 
permasalahan lingkungan di daerah aliran sungai dan wilayah pesisir, Yogyakarta: Biro Penerbitan Fakultas Geografi UGM

Ichwana, Z. N. (2014). Pengaruh aspek biofisik dan partisipasi masyarakat untuk pengelolaan sumberdaya air di Daerah Aliran Sungai Krueng Peusangan Aceh. Prosiding Seminar Nasional Sains dan Teknologi Lingkungan I (pp. 127-137). Padang.

Indriyawati, E. (2009). Antropologi. Jakarta: Pusat Perbukuan Departemen Pendidikan Nasional.

Kogoya, P. (2015). Praktik tradisi ritual bakar batu babi pada masyarakat Etnik Dani dan Damal di Kampung llaga Kabupaten Puncak Provinsi Papua. Denpasar. Tesis. Pascasarjana Universitas Udayana

Mabe, J., Simbala, H., \& Roni, K. (2016). Identifikasi dan pemanfaatan tumbuhan obat Suku Dani Di Kabupaten Jayawijaya Papua. Jurnal MIPA Unstrat Online, 5(2).

Moleong, L. (2009). Metode penelitian kualitatif. Bandung: PT Rosda Karya Offset.

Nahuway, N. (2014). Kehidupan Suku Dani di atas kulit Kayu Kombouw. Skripsi. Universitas Negeri Yogyakarta.

Paimin, Pramono, I. B., Purwanto, \& Indrawati, D. . (2012). Sistem perencanaan daerah aliran sungai. $(\mathrm{H}$. Santoso \& Pratiwi, Eds.). Bogor: Pusat Penelitian dan Pengembangan Konservasi dan Rehabilitasi.

Pemerintah Provinsi Papua. (2016). Profil kependudukan Provinsi Papua 2015. Jayapura.

Purwanto. (2003). Studi etnoekologi masyarakat Dani-Baliem dan perubahan lingkungan di Lembah
Baliem, Jayawijaya Irian Jaya. Berita Biologi Volume Agustus Edisi Khusus Kebun Biologi Wamena Dan Biodiversitas Papua, 6(5).

Salminah, M., Alviya, I., Arifanti, V., \& Maryani, R. (2014). Karakteristik ekologi dan sosial ekonomi lanskap hutan pada DAS kritis dan tidak kritis: Studi kasus pada DAS Baturusa dan DAS Cidanau. Jurnal Penelitian Sosial Dan Ekonomi Kehutanan, 11(2), 119136.

Sari, D., Barchia, M., \& Hermawan, B. (2012). Karakteristik biofisik dan sosial ekonomi yang mempengaruhi produktivitas lahan sawah pada Daerah Aliran Sungai Padang Guci Kabupaten Kaur. Jurnal Penelitian Pengelolaan Sumber Daya Alam Dan Lingkungan, 1(1), 29-34.

Tim Sintesis Penelitian Balai Pembangunan Wilayah Jalan (2008). Percepatan pembangunan pertanian di Papua berbasis sumber daya. Pengembangan Inovasi Pertanian, 1(2), 141-148.

Suprayogi, S., Purnama, S., \& Darmanto, D. (2015). Pengelolaan Daerah Aliran Sungai (Edisi Kedua). Yogyakarta: Gadjah Mada University Press.

Suradisastra, K., \& Pasandaran, D. E. (2012). Tata pengelolaan yang baik dalam pengelolaan DAS. http://www.litbang.pertanian.go.id/b uku/membalik-kecenderungandegrad/BAB-V-7.pdf.

Taena, W. (2016). Kelembagaan daerah aliran sungai wilayah perbatasan negara yang adaptif terhadap perubahan iklim dalam pembangunan yang berkelanjutan (Kasus Daerah Aliran Sungai Tono di Pulau Timor). Tesis. Pascasarjana Institut Pertanian Bogor. 
Tresnadi, H. (2008). Pengelolaan DAS dengan pendekatan ekosistem: Studi kasus analisis debit Sungai Bone dan Bolango, Provinsi Gorontalo. Jurnal Hidrosfir Indonesia, 3(2), 95-104.

Triono, N. (2010). Kajian hubungan geomorfologi DAS dan karakteristik hidrologi. Institut Pertanian Bogor.

Veronica, L. (2013). Memahami sistem pengetahuan budaya masyarakat pegunungan tengah, Jayawijaya, Papua dalam konteks kebencanaan. Antropologi Indonesia, 34(2), 134151.

Yasin, F. (2015). Strategi pengembangan sektor pariwisata di Kabupaten Jayawijaya. Tesis. Program Pascasarjana Universitas Terbuka. 